\title{
Impact of Gaming Simulation of Garbage Classification on Foreign Residents in Japan
}

\author{
Yuri Okunishi, ${ }^{1, *}$ Tomoko Tanaka ${ }^{2}$ \\ ${ }^{1}$ School of Education, Okayama University of Science, Okayama City, Japan. \\ ${ }^{2}$ Graduate School of Humanities and Social Sciences, Okayama University, Okayama City, Japan.
}

\begin{abstract}
How to cite this paper: Yuri Okunishi, Tomoko Tanaka. (2021). Impact of Gaming Simulation of Garbage Classification on Foreign Residents in Japan. The Educational Review, USA, 5(5), 106-116.

DOI: 10.26855/er.2021.05.001
\end{abstract}

Received: March 15, 2021

Accepted: April 16, 2021

Published: May 13, 2021

Corresponding author: Yuri Okunishi, School of Education, Okayama University of Science, Okayama City, Japan.

Email: okunishi@ped.ous.ac.jp

\begin{abstract}
A gaming simulation of garbage classification for foreign residents was conducted as a psycho-educational learning activity that has cognitive, behavioral, and emotional impact and reduces psychological resistance. Fourteen foreign residents (mean age: 28.9 years; mean length of stay in Japan: 48.6 months) joined the game. The participants attempted the quiz individually, with hints, and using the materials from the local government. The classification system with the original materials was explained to them, and they practiced teaching it to one another. They reported increased self-confidence, knowledge, and awareness of the system's importance and reduced perceptions of difficulty, impossibility, and troublesomeness of the garbage classification. They further reported that they could use the game experiences in their daily lives. Positive changes in the participants suggested that this game had some effect on their social life skills. However, some participants were perplexed at the complexity of the classification. Optimization of the learning contents for participants based on individual differences is a future task.
\end{abstract}

\section{Keywords}

Foreign residents in Japan, Garbage classification, Gaming simulation, Social life skills, Cross-cultural adaptation

\section{Introduction}

In recent years, the number of people moving to Japan from overseas has been increasing. The number of foreign residents at the end of 2018 was 2,731,093, an increase by 169,245 (6.6\%) from the end of the previous year (Immigration Bureau, Ministry of Justice, 2019). Since the number of foreign residents in Japan has increased, problems have arisen in the relationship between foreign and Japanese residents regarding their daily lives (Tanaka, 2013). In a study conducted by Kitahara (2013) on Gunma Prefectural Housing, she mentions the problem of garbage disposal by foreigners. Kitahara (2013) reported cases of "abandonment of oversized garbage such as furniture and home appliances" and "leaving garbage without observing the designated day of the week".

On the other hand, foreigners are also confused by unfamiliar garbage disposal methods. It is challenging to understand the detailed garbage classification methods in Japan and its disposal according to the rules designated for each region. This is due to the differences in garbage systems between Japan and other countries. To alleviate the difficulties faced by cross-cultural residents, relevant information that leads to concrete actions and educational support in making the information useful would be helpful. It is worthwhile to devise methods that support sociocultural adaptation.

Sako and Tanaka (2018) categorized intercultural social skills, or guidelines for living in a cross-cultural environment, into social life skills and interpersonal skills that include learning how to live in a cross-cultural environment and un- 
derstanding and using cultural behaviors and tips for interacting with people of different cultures, respectively. From this perspective, learning how to dispose of garbage amounts to learning how to live in a social environment, which is a social skill. Furnham and Bochnermo (1987), who proposed that social skills are a countermeasure to cultural shock, included the use of public transportation and hospital visits in their skills learning. In the broader sense of intercultural social skills, social procedures are also covered as part of cultural learning to live harmoniously in a community.

In this study, we developed educational support measures for foreign residents in Japan from countries with different waste disposal systems, focusing on their waste disposal methods. Diverse groups of foreigners live in communities; however, unlike foreign students who are in educational institutions, their educational opportunities are limited. Because it is difficult to find a structured orientation, an event form that is easier to participate in is required. This is the reason behind our idea of using a game format that would make it enjoyable to learn how to separate garbage.

In a broader sense, participatory learning using games has been widely used in medical practice, welfare, health, and other fields. It enables people to prepare in virtual reality before encountering difficult situations in reality and to organize their experiences after the event. Notably, as argued by Sugimoto (2008), augmented reality can be used in learning support methods. When games are used as educational activities, they have the potential for wide application as a form of education, with three aspects of psychological impact: cognitive, behavioral, and emotional. Well-known examples are Burnga (Steinwachs, 1990), which is used to teach intercultural communication and disaster prevention games (Yamori, Furukawa, \& Amishiro, 2005; Yoshikawa, Yamori, \& Sugiura, 2009), which are used in communities.

Fujihara (2007) called a gaming simulation a process in which multiple participants followed a set of rules, exchanged information through communication, and made decisions and judgments to solve certain problems in a virtual space that abstracted reality. He also stated that games could be tailored for various subjects. Learning support with a recreational nature can create flexible ideas. In this study, a game-style educational tool was devised to create an opportunity for awareness and action regarding waste separation. The game was conducted with foreign residents living as members of a local community, and their responses were analyzed.

\section{Method}

\subsection{Participants}

On a certain day in 2020, a group of foreign residents who wished to participate in the game gathered at a cross-cultural exchange program for citizens in X City, a medium-sized city in western Japan. We started with 16 participants and analyzed the responses of the 14 participants who participated until the end of the study. Of these, 10 were men and 4 were women. The mean age was 28.9 years $(\mathrm{SD}=10.1)$, and the range included people from their teens to their fifties. The mean length of stay in Japan was 48.6 months (SD=60.9), and the length ranged from 3 months to 17 years. Their regions of origin were East Asia (2 persons), Southeast Asia (8 persons), South Asia (1 person), West Asia (1 person), North America (1 person), and Oceania (1 person). Regarding the type of residence, they all lived in apartments or similar residences, where they disposed of their own garbage.

\subsection{Procedure}

The procedural flow is illustrated in Figure 1. Before and after the game, we asked the participants to answer a questionnaire on how they disposed of garbage in their daily lives and their views about the game. The game was titled "Aim with Gomiman! Garbage Master" and had an original character named "Gomiman". The participants were given Gomiman stickers as a souvenir and a special calendar with Gomiman illustrating the three points of garbage separation. In the illustration (Figure 2), the first step is to determine whether the item to be disposed of should go to the regular collection, could become a resource, or is burnable, and then follow the branches of the algorithm. Then, the participants had to reach an appropriate category among combustible waste, non-combustible waste, recyclable waste, oversized waste, and waste that could not be disposed of to the local garbage collectors.

In the game, the participants were asked about waste separation categories (Table 1). The correct answers were announced and explained, and then a special calendar was used to summarize the waste separation methods in X city. At the end of the game, the participants were asked to teach one another about waste separation to reinforce their understanding. The sessions were conducted in English and Japanese.

\subsection{Composition of the game}

The objectives of the game were "to acquire knowledge about garbage separation" and "to learn ways to deal with situations when one does not know how to separate garbage". In the game, plastic bottles, magazines, and other items were presented with pictures, and the participants were asked to determine the sorting categories. First, the participants 
tried to answer the questions individually; second, with hints; third, in cooperation with others; fourth, by looking at materials from the local government. The intention was to emphasize the importance of not giving up or neglecting the problem, and instead looking for clues and using them to answer correctly.

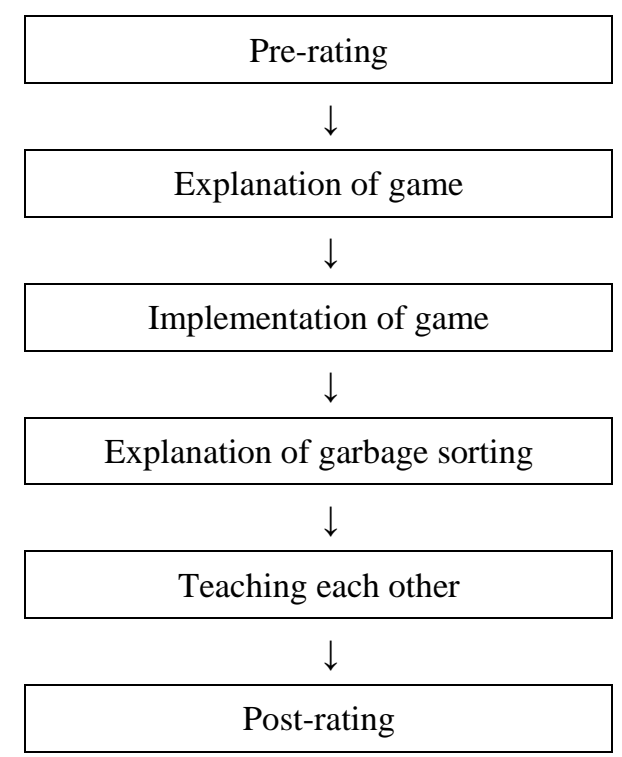

Figure 1. Procedural flow.

OO市ごみ搭と 3つのボイント 〜これで迷わない!〜

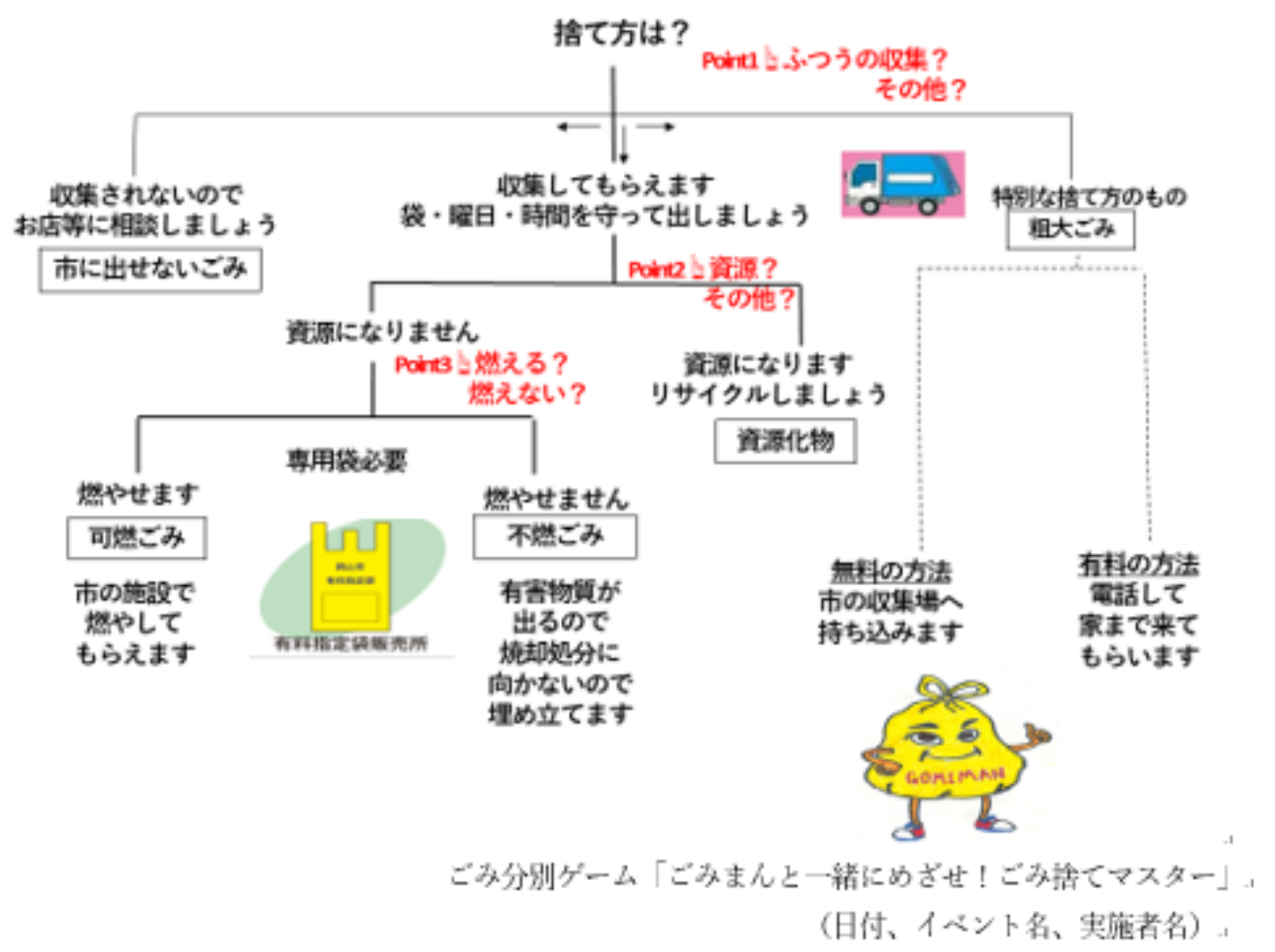

Figure 2. Decision points for waste separation. 
Table 1. Waste sorting categories in X city, and tips in Game B

\begin{tabular}{|c|c|c|c|}
\hline Game & Garbage & Sorting Category & Tip \\
\hline \multirow{5}{*}{ A } & Raw garbage & Combustible waste & \\
\hline & Plastic bottles & Recyclables & \\
\hline & Glassware & Incombustible waste & \\
\hline & Aluminum foil & Combustible waste & \\
\hline & Washing machine & Home appliances and small home appliances & \\
\hline \multirow{5}{*}{$\mathrm{B}$} & Umbrella & Non-combustible waste & The frame of the umbrella is made of metal. \\
\hline & Clothes & Recyclables & Can be recycled \\
\hline & Athletic shoes & Combustible waste & Made of cloth and rubber \\
\hline & Sofa & Bulky waste & $\begin{array}{l}\text { Requires an appointment for collection because it } \\
\text { is large. }\end{array}$ \\
\hline & Magazines & Resources & Can be recycled \\
\hline \multirow{5}{*}{$\mathrm{C}$} & Frying pan & Incombustible waste & \\
\hline & Tires & Cannot be sent to the city & \\
\hline & Staple needles & Music sheet waste & \\
\hline & Bookshelf & Bulky waste & \\
\hline & Empty cans & Resources & \\
\hline \multirow{5}{*}{$\mathrm{D}$} & Carpets & Bulky waste & \\
\hline & Cardboard & Recyclables & \\
\hline & Styrofoam & Combustible waste & \\
\hline & TV & Home appliances and small home appliances & \\
\hline & Fire extinguisher & Cannot be sent to the city & \\
\hline
\end{tabular}

Each session was paced with a one-to-two-minute time limit for answering. To increase the fun in answering the questions, a "certificate of success" was awarded to the high scorers in each session to commemorate their achievement. The question content was chosen by two international students majoring in psychology and two Japanese students based on materials from the local government. Hint selection was based on a comparison of answers with and without hints by 21 Japanese university students, focusing on those hints that had a significant effect on getting closer to the correct answer. Regarding the difficulty level, we surveyed 27 Japanese students and found that the proportion of correct answers to the questions used was $66.1 \%$.

The following four games, A, B, C, and D, were conducted in the same order.

A: Solo quiz version

One participant selected a waste category. The garbage was projected onto a screen with pictures. A quiz-style game with five questions, five choices, and five points.

B: Solo demonstration version

A game in which the participants made the same decision as in the A version, independently but with action. Participants had to sort and put two cards with names and pictures of garbage into two of the five categories of boxes designated by the city. Each card was worth two points, for a total of 10 points. The participants were allowed to look at the hint cards provided; however, one point was deducted for each hint card.

C: Cooperative demonstration version

A game in which four participants worked in groups and consulted with one another to decide how to sort garbage. 
The idea was to put all five cards, each with a name and a picture of garbage, into the boxes of the five different sorting categories, with a perfect score of 5 points.

D: Solo material version

Each participant answered a quiz with five questions, five choices, and a perfect score of five points, by referencing the city brochure. Some questions were not included in the brochure. The garbage was projected using pictures.

\subsubsection{Before the game}

The participants were asked about their age, sex, and length of stay in Japan. They were asked whether they had been warned about garbage separation and content. They were also asked about differences in garbage disposal between Japan and their home country.

\subsubsection{After the game}

The participants were asked to rate the game on a 5-point scale on items such as fun, difficulty, confusion, well-performed, not performed as well as expected, understood the importance of cooperation, understood the importance of investigation, would recommend the game to others, could apply the experience to real life, and would like to play again. They were also asked if they used hint cards, why they used them, and about the results.

\subsubsection{Before and after the game}

We requested some evaluations. We asked them to rank 24 items on a 5-pointscale, related to awareness about garbage separation before and after the game, to see if there were any changes. The evaluations included perceptions of confidence, interest, motivation, knowledge, effort, compliance, importance, difficulty, and troublesomeness of garbage separation, the evaluation of the current situation regarding the lack of explanation on how to dispose of garbage, incomprehensibility of materials, meaninglessness, and excessive details. Furthermore, the evaluation included perceptions of garbage disposal, displayed through items such as "I think I know the correct methods," "I think I can do it if I am taught," "I think I can teach others," "I think it is too detailed to deal with," "I think I make mistakes without realizing it," "I think I just throw away without understanding," and "I think it is enough if I can do it to some extent."

Additionally, the participants were asked about their behaviors when they did not know how to sort the garbage into five categories and were given a choice between four options: asking a friend, looking it up in an app, looking it up in a city brochure, or just throw it away without consideration. Regarding these items, the participants were asked about their daily activities before and after the game. They were also asked about their future intentions.

\section{Results and Discussion}

\subsection{Experiences of being warned about how to dispose of garbage}

Of the 14 respondents, 6 (42.9\%) had experienced being warned about how to dispose of garbage. To summarize the descriptions, most respondents (5, 85.7\%), used wrong ways to separate waste. Regarding responses, four out of six responded on the spot, and two (50\%) learned a lesson later.

\subsection{Differences in garbage disposal between the country of origin and Japan}

Of the 13 respondents, 12 (92.3\%) described their method of waste separation. The descriptions varied from no sorting done, collections done by companies and not by individuals, to plastic being separated from combustible materials. One respondent (7.6\%) mentioned that citizens were required to use the specified garbage bags in X city.

\subsection{Game performance and reflection}

The game scores averaged $3.36(\mathrm{SD}=1.34)$ for the A version, $5.64(\mathrm{SD}=0.81)$ for the $\mathrm{B}$ version, $4.57(\mathrm{SD}=0.49)$ for the $\mathrm{C}$ version, and $3.50(\mathrm{SD}=1.18)$ for the $\mathrm{D}$ version. No one answered all questions correctly.

When the participants were asked to reflect on the game, the highest-rated items were, "I understood the importance of cooperation" and "I think I can use this game in real life" (Table 2); next were, "I think I did well in the game," "I understand the importance of investigating," and "I would recommend this game to others;" the next two were, "I enjoyed the game” and "I want to play the game again.” The lowest scores were for "I couldn’t play the game as well as I expected," followed by "The game was difficult" and "I got lost a lot during the game."

In other words, the participants felt that they could apply the experience from the game to real life. They understood that it was important to cooperate and investigate when they did not know how to sort. They found the game enjoyable and were able to play quite well. 
Table 2. Game Reflection

\begin{tabular}{|c|c|c|c|}
\hline & Question items & $M$ & $S D$ \\
\hline (1) & The game was difficult. & 2.50 & 1.24 \\
\hline (2) & I enjoyed the game. & 3.64 & 0.97 \\
\hline (3) & I think I did well in the game. & 3.79 & 0.67 \\
\hline (4) & I couldn't play the game as well as I expected. & 2.00 & 1.07 \\
\hline (5) & I understood the importance of investigation. & 3.79 & 0.67 \\
\hline (6) & I understood the importance of cooperation. & 4.14 & 0.64 \\
\hline (7) & I got lost a lot in the game. & 3.14 & 1.25 \\
\hline (8) & I want to play the game again. & 3.50 & 1.18 \\
\hline (9) & I would recommend this game to others. & 3.79 & 1.21 \\
\hline$(10)$ & I think I can use this game in real life. & 4.14 & 0.83 \\
\hline
\end{tabular}

\subsection{Use of hint cards}

In the B version, three respondents used the hint cards and, consequently, said that it became easier for them to sort garbage. There were 10 who did not use the cards, eight of whom wrote down their reasons: five (63\%) were confident in their answers and three (37\%) wanted to test their knowledge. It was noted that they seemed to enjoy gameplay.

\subsection{Learning from the game}

The answers to the question "What do you think you learned from today's game?" were as follows. For version A, nine respondents reported learning two things: waste separation (6 respondents, $66.6 \%$ ), awareness of things they were not good at (1 respondent, 11.1\%), and other (2 respondents).For the Bversion, 9 respondents reported learning about waste separation (7 respondents, $77.8 \%$ ) and other (2 respondents). About 11 respondents reported learning three things: knowledge of waste sorting (6 respondents, 54.5\%), the positive impact of cooperation ( 2 respondents, 18.2\%), and the negative impact of cooperation (3 respondents, $27.3 \%$ ), which could be attributed to the fact that the answers given by the group were either correct or incorrect. For the Dversion, three things were learned by 10 respondents: garbage separation (4 respondents, $40.0 \%$ ), the positive effects of using the material (2 respondents, 20.0\%), the negative effects of using the material (3 respondents, 30.0\%), and other (1 respondent), with the last referring to the difficulty of the translated version of the Japanese material.

Learning waste separation was common among all four game versions. This indicates that games were perceived as useful in improving knowledge about waste separation.

\subsection{Changes before and after the game}

\subsubsection{Change in awareness of waste separation before and after the game}

Significant improvements from before to after the game were observed in (1) self-confidence, (8) knowledge, and (14) perception of importance (Table 3). Clearly, the game experience increased their awareness of the importance of waste separation as a norm, helped them understand their own level of knowledge, and enhanced their confidence.

Focusing on individual differences, the number of people whose grades either increased or decreased were compared. The initial grades were extracted in the instances in which the difference was more than double. Besides the above three items (1, 8, and 14), more people showed positive changes in the following six areas (Table 4): an improvement in the perception of (9) understanding, (10) ability to teach others, and (12) ability to sort if taught, while there was a decrease in the perception of (5) difficulty, (6) impossibility, and (16) problems related to accurate sorting. Overall, although they thought it was difficult, they felt that they could separate the materials if they were taught, felt that they understood, and wanted to teach others.

The participants came from countries with different waste disposal systems and had lived in Japan for an average of four years; about $40 \%$ of them had been warned about their waste disposal. The pre-game ratings suggest that the participants made an effort to separate garbage in their daily lives but also found it difficult. 
Table 3. Changing attitudes about waste sorting before and after the game

\begin{tabular}{|c|c|c|c|c|c|c|c|c|c|c|c|}
\hline & & \multicolumn{2}{|c|}{ before } & \multicolumn{2}{|c|}{ after } & \multirow[b]{2}{*}{ increase } & \multirow[b]{2}{*}{ decrease } & \multirow[b]{2}{*}{ same } & \multirow[b]{2}{*}{$\begin{array}{c}T-v a \\
\text { lue }\end{array}$} & & \multirow[b]{2}{*}{$d f$} \\
\hline & & $M$ & $S D$ & $M$ & $S D$ & & & & & & \\
\hline 1 & I am confident in my garbage sorting. & 3.50 & 0.82 & 4.36 & 0.61 & 8 & 0 & 6 & 3.38 & * & 13 \\
\hline 2 & I am interested in garbage sorting. & 3.93 & 1.10 & 3.79 & 1.26 & 2 & 2 & 8 & 0.49 & & 13 \\
\hline 3 & I am motivated to sort garbage. & 4.07 & 0.80 & 4.21 & 0.67 & 3 & 1 & 8 & 1.00 & & 13 \\
\hline 4 & I want to get better at sorting garbage. & 4.57 & 0.62 & 4.43 & 0.82 & 1 & 3 & 8 & 1.00 & & 13 \\
\hline 5 & I think it is difficult to sort garbage. & 3.93 & 0.70 & 3.50 & 1.35 & 2 & 6 & 4 & 1.31 & & 13 \\
\hline 6 & $\begin{array}{l}\text { I think it is impossible to sort garbage } \\
\text { correctly. }\end{array}$ & 2.71 & 1.03 & 2.29 & 0.88 & 2 & 4 & 6 & 1.47 & & 13 \\
\hline 7 & $\begin{array}{l}\text { I think I make mistakes in sorting } \\
\text { garbage without realizing it. }\end{array}$ & 3.14 & 0.99 & 2.86 & 1.12 & 3 & 4 & 5 & 0.89 & & 13 \\
\hline 8 & $\begin{array}{l}\text { I think am knowledgeable about sort- } \\
\text { ing garbage. }\end{array}$ & 3.00 & 1.36 & 3.79 & 0.94 & 7 & 0 & 6 & 2.92 & $* *$ & 13 \\
\hline 9 & $\begin{array}{l}\text { I know the correct way to sort gar- } \\
\text { bage. }\end{array}$ & 3.43 & 1.12 & 4.07 & 0.59 & 6 & 1 & 7 & 2.09 & & 13 \\
\hline 10 & $\begin{array}{l}\text { I think I can teach others how to sort } \\
\text { garbage. }\end{array}$ & 3.29 & 1.39 & 3.71 & 0.88 & 6 & 2 & 8 & 1.10 & & 13 \\
\hline 11 & $\begin{array}{l}\text { I think I follow the rules of garbage } \\
\text { sorting. }\end{array}$ & 4.00 & 0.85 & 4.00 & 0.38 & 2 & 4 & 4 & 0.74 & & 13 \\
\hline 12 & $\begin{array}{l}\text { I think I can do it correctly if some- } \\
\text { one teaches me how to do it. }\end{array}$ & 4.15 & 0.66 & 4.57 & 0.62 & 6 & 0 & 7 & 1.71 & & 13 \\
\hline 13 & $\begin{array}{l}\text { I think it is important to sort garbage } \\
\text { for the environment. }\end{array}$ & 4.86 & 0.35 & 4.86 & 0.35 & 1 & 1 & 12 & 0.00 & & 13 \\
\hline 14 & $\begin{array}{l}\text { I think it is important to sort garbage } \\
\text { as a social norm. }\end{array}$ & 4.43 & 0.82 & 4.93 & 0.26 & 5 & 0 & 7 & 2.19 & $* *$ & 13 \\
\hline 15 & $\begin{array}{l}\text { I throw garbage away without under- } \\
\text { standing how to sort it. }\end{array}$ & 2.93 & 1.22 & 2.79 & 1.26 & 2 & 5 & 7 & 0.56 & & 13 \\
\hline 16 & $\begin{array}{l}\text { I find it troublesome to sort and dis- } \\
\text { pose of garbage. }\end{array}$ & 2.57 & 0.98 & 2.29 & 1.39 & 3 & 7 & 4 & 0.67 & & 13 \\
\hline 17 & $\begin{array}{l}\text { I have not received sufficient expla- } \\
\text { nation about waste separation. }\end{array}$ & 3.14 & 0.83 & 2.93 & 0.96 & 5 & 6 & 3 & 0.59 & & 13 \\
\hline 18 & $\begin{array}{l}\text { Materials on waste separation are } \\
\text { difficult to understand. }\end{array}$ & 3.14 & 0.83 & 3.21 & 1.15 & 5 & 4 & 3 & 0.20 & & 13 \\
\hline 19 & $\begin{array}{l}\text { I want detailed information on how to } \\
\text { dispose of garbage in my native lan- } \\
\text { guage. }\end{array}$ & 3.36 & 1.29 & 3.36 & 1.34 & 2 & 3 & 9 & 0.00 & & 13 \\
\hline 20 & $\begin{array}{l}\text { I think it is enough to be able to sort } \\
\text { garbage to a certain extent. }\end{array}$ & 4.21 & 0.94 & 4.50 & 0.82 & 5 & 2 & 7 & 1.30 & & 13 \\
\hline 21 & $\begin{array}{l}\text { I think garbage separation method is } \\
\text { too detailed and difficult to under- } \\
\text { stand. }\end{array}$ & 3.46 & 1.15 & 3.57 & 1.24 & 4 & 2 & 7 & 0.61 & & 13 \\
\hline 22 & $\begin{array}{l}\text { I don't think it makes much sense to } \\
\text { separate garbage. }\end{array}$ & 1.79 & 0.94 & 1.57 & 0.62 & 3 & 4 & 7 & 0.82 & & 13 \\
\hline 23 & $\begin{array}{l}\text { I don't think it's important how we } \\
\text { dispose of garbage. }\end{array}$ & 1.86 & 1.30 & 2.21 & 1.26 & 6 & 2 & 6 & 0.69 & & 13 \\
\hline 24 & $\begin{array}{l}\text { I am making efforts to sort garbage } \\
\text { accurately. }\end{array}$ & 3.93 & 0.96 & 4.14 & 0.99 & 3 & 2 & 9 & 0.90 & & 13 \\
\hline
\end{tabular}

Notes. ${ }^{*} p<0.01,{ }^{* *} p<0.05$. 
Table 4. Direction of change in rating of awareness of sorting litter before and after the game for each participant

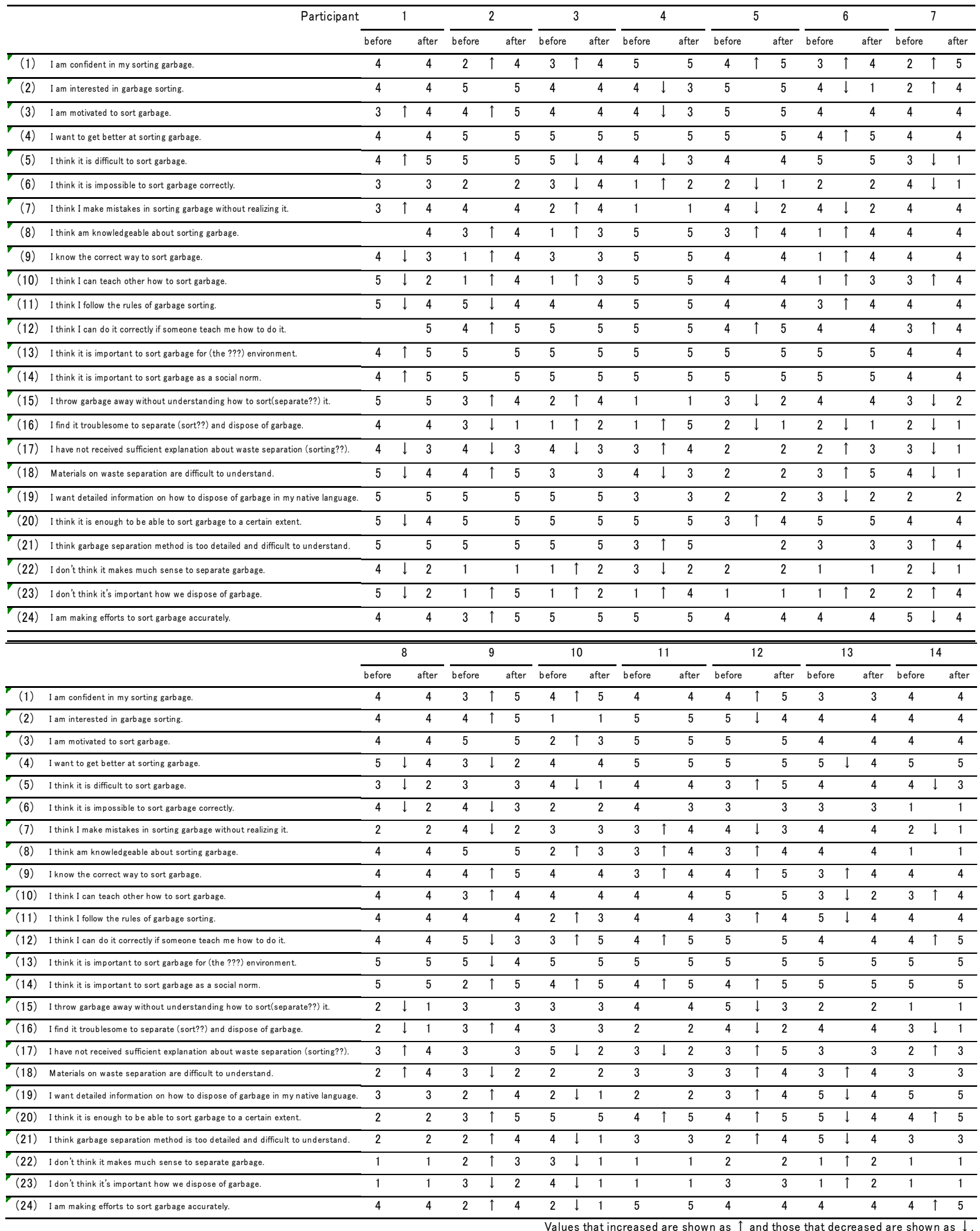


In contrast, negative changes were observed in the five areas. First, more people decreased their awareness of (11) following the rules and increased their lack of confidence in sorting (15). This could be because they gained knowledge and realized the inaccuracy of how they disposed of garbage on a daily basis. More people increased in the three categories of (20) "It is good if I can do it to some extent," (21) "It is too detailed and difficult to understand," and (23) "Sorting is not so important." This may be a sign of resistance to the complexity of sorting.

Overall, positive changes occurred, although negative responses were observed in some cases. As an example of the relatively large number of negative changes, Participant No. 3 showed an increase in the perception of garbage sorting as (6) “impossible," (16) “troublesome,” and (22) “unimportant.” In the case of No. 9, (4) "want to become better” and (13) "important" decreased, while (16) "troublesome" and (22) "unimportant" increased. In these cases, the young people who stayed in Japan for a relatively short time may have had a greater sense of burden due to a combination of unfamiliarity with Japanese life and social life.

We summed up the scores for the A: single quiz and D: stand-alone material versions, which seemed to reflect a rela tively high level of individual understanding. The B: solo demonstration version is not necessarily an individual decision-making process because other participants' answers are visible in the demonstration process, while the C: cooperative demonstration version involves consultation. The three participants with the highest scores were No. 2, No. 5, and No. 11. No particular negative changes were observed in the upward and downward changes in the values. Although their attributes varied, it was assumed that they had stable knowledge and performance and were unlikely to have a sense of impossibility regarding sorting.

Before the game, the participants were asked what they would do if they did not know how to separate garbage; they were asked the same question after the game. The most common response before and after the game was to ask a friend, with a mean of $3.36(\mathrm{SD}=1.11)$ before the game and $3.43(\mathrm{SD}=1.12)$ after the game.

\section{General Discussion}

The participants tried to play a garbage-sorting game by themselves or in teams. Although the questions were difficult even for Japanese students, the participants were not completely helpless and enjoyed answering the questions even when they were confused. The changes in the ratings suggest that the participants felt that they had gained knowledge and confidence in waste separation through this game experience and that they were more aware of the importance of waste separation. In other words, this game brought about positive changes in the awareness of waste separation. In addition, the post-game reflections revealed that the participants understood the importance of investigation and cooperation.

In conclusion, while the game was played recreationally, it had a certain effect as a learning method for social life skills by raising awareness about waste separation and motivating people to think about how to deal with situations when they do not know how to separate waste and take action. The game format has the advantage of lowering the psychological resistance of the participants, making it possible to handle this subject matter smoothly, although it tends to be heavy-handed.

In this case, the game was devised as a social life skills learning tool; however, when we look at other intercultural social and interpersonal skills learning sessions, the aspect of learning while having fun is common. Tanaka and Nakajima (2006) and Mikushiand Tanaka (2013) constructed small group sessions based on interpersonal skills training in clinical psychology, in which participants engage in role-play and interact using task situations. In this study of social life skills, the game proceeds with individuals placed in a virtual scene to express their proactive behavior. In the field of medical safety, there are examples of incorporating activities to hone interpersonal skills into games for learning safety behaviors (Yamamoto, Tanaka, Hyodo, \& Katayama, 2018). A possible arrangement would be to combine the garbage disposal game with the role-playing of interpersonal interaction situations related to garbage disposal, followed by learning interpersonal skills. According to Fujihara (2007), gaming simulation was not only social skill learning of interpersonal behavior but also imagery training through the prisoner's dilemma game and movie watching. Learning techniques that utilize human imagination have a wide range of applications and may be applied in various ways to this subject.

While positive changes occurred, it should be noted that there were also some confused responses; for example, "the sorting was too detailed and impossible to do accurately." Since the number of participants was limited, a detailed analysis was not possible. However, it can be expected that there will be considerable individual differences in what people face in terms of how they dispose of their garbage in their transition to a new environment, where they have problems, and what kind of garbage disposal behavior they engage in. The challenge for the future is to make the game more innovative, considering individual differences, to achieve a higher effect on more people.

For example, in this case, a variety of participants played the game together using the same problems; however, it 
would be a good idea to optimize the tasks according to the difficulty level of the learners. To avoid overwhelming the participants, the game could be structured with easy-to-understand explanations, followed by an opportunity to try again and repeat the game several times to gain experience and success. A sense of accomplishment and confidence are expected to improve self-efficacy. In Maemura (2007), the game deepens the discussion, followed by a debriefing. In this way, for example, it may be a good idea to have an experience in which each person's starting point is respected by introducing their native country garbage disposal method during the discussion. In some cases, competitive environments, such as using paid garbage bags as prizes or group competitions, could be used to increase the motivation and appeal of the game.

The response to the game can be understood as a reflection of the waste disposal situation in the community. Some questioned the detailed separation of garbage. According to Takeda (2007), there are some cases where segregation is costly and creates a burden on the environment. If we consider that eco-education, which claims that the more we separate, the better it is for the environment, includes some irrational aspects, it is not surprising that some residents have doubts about the system in Japan. However, living in a community as a member implies that one must deal with immediate norms. As far as resistance due to differences in common sense and unfamiliarity is concerned, we can think of ways to alleviate it. To do so, we need to be aware of the gaps associated with environmental transition and the perspective of people who live in different cultures. If there is insufficient support for the process of cross-cultural adaptation, it may become an imposition without understanding, which limits the effectiveness of the program.

The local government has been making efforts to provide translated explanatory materials to Japanese residents, and the participants in this case had received them when they moved to X City; despite this, difficulties were encountered. Since the system of waste separation and the framework for recognition by foreign residents differ depending on their country of origin, it is presumed that it is difficult to uniformly give them instructions using the same materials. To make new garbage disposal behavior take root, we may be able to use stage-based guidance, as seen in health education. First, inform them of the importance of littering, prepare their interest and motivation, then provide them with the knowledge and means to do it, watch them do it, adjust and encourage them, and help them continue. For learning interpersonal skills (Tanaka, 2012), there is a preparatory stage that promotes cultural awareness and understanding before learning behaviors to cope with difficulties for the participants to develop a convincing attitude to learn. If games are tools that can promote changes in awareness and attitudes, they can conceivably be used to situate them within the psychological preparation process.

If the starting point is to be aware of the differences, it would be ideal to have the following mechanisms at the time of moving in: preparing a sheet to check the differences between Japan and their country and identify the changes that need to be made, so that they can identify what needs to be changed and clarify their action goals. In addition, the waste disposal system in Japan should be carefully explained to convince the participants of the practical and concrete reasons for waste separation and to increase their conviction of the necessity of such behavior. The actual rules for recycling and garbage disposal are set within the system of the municipality concerned. Convincing people of the framework itself will be the starting point to encourage them to take action.

In the illustration distributed currently, we narrowed down the points on how to dispose of garbage to three. For those who tend to be overwhelmed by the complexity of the garbage disposal system, a concise presentation would help them choose their actions. Many of the participants said that they would ask others if they did not understand; therefore, it would be important to have knowledgeable supporters around to help. It would be desirable to have an awareness of and ideas for living together, rather than a power relationship in which group norms are set as common sense and manners, and social pressure is applied to deviations.

Learning social life skills for cross-cultural residents will require a mindset that looks at the reality of environmental transitions and organizes the differences in a contrasting way, identifying the points that require adjustment and the reasons for it. Those who stay in a different culture are confronted with differences in their environment, and cross-cultural adaptation cannot be achieved in a single step. It is necessary to understand that there is a process that requires effort and time to gradually overcome the gap and adapt to the new life. When welcoming newcomers to a community, it is important to carefully explain the situation and guide them through changes. It is hoped that this will take root as a basis for a symbiotic society, where both hosts and guests live together as members of a local community.

\section{Acknowledgements}

1. Supported by Grant-in-Aid for Scientific Research, Basic B (15H0345611).

2. We have reconstructed the data from Reo Morishige's graduation research in 2019, Faculty of Letters, Okayama University. We thank him for his willingness and cooperation in the presentation.

3. We would like to express our deepest gratitude to the Conference of Okayama International NGO Network 
(COINN) and local residents of X City for their cooperation in international exchange.

4. We would like to thank Ayşe Ilgın Sözen for providing us with the wonderful illustrations.

\section{References}

Fujihara, T. (2007). Foreword in Fujihara, T. (Ed.), Gaming Simulation of Human Relations: Seeking the Path to Coexistence. Kitaoji Shobo (in Japanese).

Furnham, A. and Bochner, S. (1982). Social difficulty in a foreign culture: An empirical analysis of culture shock In S. Bochner (Ed.), Cultures in contact: Studies in cross-cultural interactions. Oxford: Pergamon Press.

Immigration Bureau, Ministry of Justice. (2019). Press Release: Number of Foreign Residents as of the End of 2018. URL (last checked 26 January 2020) http://www.moj.go.jp/nyuukokukanri/kouhou/nyuukokukanri04_00081.html. (in Japanese)

Inaba, Y. (2008). A Study on the Actual Condition of Foreign Residents in Public Housing. The Urban Planning Journal of the City Planning Society of Japan, 43-1. (in Japanese)

Maemura, N. (2007). Intercultural Exchange Games Focusing on Language Differences and Their Educational Effects in Fujihara. In Takehiro (ed.), Gaming Simulation of Human Relations: Seeking the Path to Coexistence. Kitaoji Shobo. (in Japanese)

Masanori, S. (2008). Learning Support Using Augmented Reality Method. Journal of the Japanese Society for Artificial Intelligence, 23(2), 237-242.

Mikushi, K. and Tanaka, T. (2013). Social skills learning focused on Japanese indirect expressions: An experimental session using teaching aids such as cultural assimilators. Progress in Asian Social Psychology Series, Volume 9, Towards Social Harmony: A New Mission of Asian Social Psychology, 132-154.

Reiko, K. (2013). Study of Foreign Households in Public-Use Housing in Isesaki City, Gunma Prefecture and Local Government Initiatives. Journal of the Architectural Institute of Japan, 78(688), 1241-1247. (in Japanese)

Sako, K. and Tanaka, T. (2018). An examination of social skills of intercultural stay in Japanese in Brazil: From the perspective of social life skills and interpersonal skills. Tabunka Kankei Gaku, 15, 3-17. (in Japanese)

Steinwachs, B. (1990). Barnga: A Simulation game on cultural clashes. ME: Intercultural Press.

Takeda, K. (2007). Why Lies are Covered in Environmental Problems. Yosen-sha. (in Japanese)

Tanaka, H. (2013). Zainichi Gaikokujin Dai-san Ban: Hokoku no Kabe, Kokoro no Mizo, Iwanami Shoten. (in Japanese)

Tanaka, T. (2012). A cross-cultural psycho-educational program for cross-cultural social skills learning to international students in Japan: Focusing on the AUC-GS learning model. Japanese Journal of Applied Psychology, 38, 76-82.

Tanaka, T. (2018). Scenario simulation and skill learning for the process of human error occurrence and accident prevention. Journal of Japanese Society for Simulation Medical Education, 6, 23-29. (in Japanese)

Tanaka, T. and Nakashima, M. (2006). A Trial of Intercultural Education Incorporating Social Skill Learning. Journal of Intercultural Education, 24, 92-102. (in Japanese)

Yamori, K., Yoshikawa, H., and Amishiro, T. (2005). Disaster Prevention Game de Manabu Risk Communication: An Invitation to Crossroads. Nakanishiya Publishing Co. (in Japanese)

Yoshikawa, H., Yamori, K., and Sugiura, J. (2009). Crossroads Next: Learning Risk Communication through Games. Nakanishiya Publishing Co. 